\title{
Role of Weddell Sea ice in South Atlantic atmospheric variability
}

\author{
Yushi Morioka $^{1, *}$, Francois Engelbrecht ${ }^{2,3}$, Swadhin K. Behera ${ }^{1}$ \\ ${ }^{1}$ Application Laboratory, JAMSTEC, Yokohama, Japan \\ ${ }^{2}$ Natural Resources \& the Environment, CSIR, Pretoria, South Africa \\ ${ }^{3}$ School of Geography, Archaeology and Environmental Sciences, University of the Witwatersrand, South Africa
}

\begin{abstract}
We investigated the role of Weddell Sea ice in atmospheric variability over the South Atlantic by conducting observational data analysis and coupled general circulation model (CGCM) experiments. Weddell Sea ice exhibits a pronounced interannual variability in early austral summer (November-January). Low sea-ice concentration (SIC) anomalies in the Weddell Sea are strongly associated with anticyclonic atmospheric circulation anomalies in the South Atlantic. Composite analysis reveals that the low SIC anomalies in the Weddell Sea may be attributed to increased solar radiation and northwesterly wind anomalies. The low SIC anomalies, in turn, contribute to warmer skin temperature in the band of $60-70^{\circ} \mathrm{S}$ and enhance the near-surface atmospheric stability north of this band, implying favorable conditions for sustaining the anticyclonic circulation anomalies in the South Atlantic. This intriguing association between the SIC and atmospheric circulation anomalies is also simulated in CGCM experiments, e.g. when the interannual sea surface temperature variability in the tropics and mid-latitudes is suppressed. These results suggest that Weddell Sea ice, which may undergo interannual variation via air-sea-ice interactions in the high latitudes, influences atmospheric variability over the South Atlantic.
\end{abstract}

KEY WORDS: Air-sea-ice interaction - Interannual variability · South Atlantic $\cdot$ Atmospheric teleconnection $\cdot$ Coupled general circulation model

\section{INTRODUCTION}

The South Atlantic Ocean undergoes significant seasonal to decadal variations in which the subtropical high, i.e. the St. Helena High, plays a crucial role (e.g. Venegas et al. 1996, 1997). In particular, the interannual variation of sea surface temperature (SST) in the South Atlantic peaks in austral summer (December-February) and is often associated with a dipole structure of SST anomalies, called the South Atlantic Subtropical Dipole (SASD; Fauchereau et al. 2003). The southward shift and strengthening of the St. Helena High are responsible not only for generating the positive phase of the SASD (Morioka et al. 2011), but also for rainfall variability over subtropical South America (Doyle \& Barros 2002) and southern Africa (Vigaud et al. 2009). Given the significant soci-

${ }^{*}$ Corresponding author: morioka@jamstec.go.jp etal impacts induced by the interannual rainfall variability, it is of great importance to accurately understand and skillfully predict atmospheric variability in the South Atlantic.

Previous studies reported remote and local influences on atmospheric variability in the South Atlantic. The atmospheric teleconnection from the South Pacific, widely known as the Pacific-South American (PSA $;$ Mo \& Paegle 2001) pattern, greatly contributes to variability in the subtropical high of the South Atlantic (Colberg et al. 2004). Since the PSA pattern does not have a particularly strong relation with the tropical Pacific climate variability, i.e. El Niño-Southern Oscillation (ENSO), the PSA pattern can be considered an atmospheric response to various internal and external factors beyond such a tropical forcing (Irving \& Simmonds 2016, O'Kane et al. 2017). The

() The authors 2017. Open Access under Creative Commons by Attribution Licence. Use, distribution and reproduction are unrestricted. Authors and original publication must be credited. 
intrinsic atmospheric variability in the mid- to high latitudes of the Southern Hemisphere, i.e. the Southern Annular Mode (SAM; Thompson \& Wallace 2000), is also an important driver of atmospheric variability in the South Atlantic (Morioka et al. 2014).

Despite many efforts devoted to understanding interannual climate variability in the South Atlantic, there remains some uncertainty in its simulation and prediction using coupled general circulation models (CGCMs; Morioka et al. 2012, Yuan et al. 2014). One factor not considered in these studies is the potential role of interannual variability in Antarctic sea ice as a driving mechanism of atmospheric variability in the South Atlantic.

The atmospheric response to sea-ice variability in the Antarctic region has been discussed in several studies. Based on observational analysis, Venegas \& Drinkwater (2001) examined the impact of sea-ice concentration (SIC) anomalies in the Weddell Sea on the overlying atmosphere during austral winter. Hudson \& Hewitson (2001) demonstrated in an atmospheric GCM study that a decrease in Antarctic sea ice may generate cyclonic anomalies in the high latitudes and anticyclonic anomalies in the mid-latitudes through changes in cyclone activity. Raphael (2003) demonstrated the Southern Hemisphere atmospheric response to the summertime sea-ice increase over the entire Antarctic using a CGCM. More recently, by analyzing observational data and CGCM model output, Wall et al. (2017) revealed that the atmospheric boundary layer in the Weddell Sea is stable over the sea ice during austral winter because sea ice inhibits heat and moisture transport from the ocean to the atmosphere, while the boundary layer is unstable and cloudy over open water.

Although the potential role of Weddell Sea ice variability in atmospheric variability has been suggested, most studies have instead focused on the physical mechanisms behind the sea-ice variability in the Weddell Sea. For example, Carleton (1988) and Yuan \& Martinson (2000) discussed a significant impact of ENSO on the interannual SIC variability in the Weddell Sea. This impact may manifest through the PSA teleconnection pattern (Yuan \& Martinson 2000). On the other hand, some studies (Liu et al. 2004, Udagawa et al. 2009, Murphy et al. 2014) provided evidence for the role of the SAM in the sea-ice variability, in addition to remote influences from ENSO. The coupled ocean-atmosphere-ice response to the SAM was also demonstrated in a CGCM framework (Sen Gupta \& England 2006).

The potential impact of sea-ice variability on atmospheric circulation has recently received much at- tention in the Northern Hemisphere in the face of rapid Arctic sea-ice reduction due to warming climate. Because of an increase in the absorbed solar radiation associated with the sea-ice reduction, the frequency of cyclones in the Barents Sea may increase (Inoue et al. 2012), with a downstream influence on the atmospheric variability over Siberia (Honda et al. 2009). The role of sea-ice variability in the boreal autumn and winter climate over the Far East has also been indicated in an atmospheric GCM experiment (Mori et al. 2014). These results of the sea-ice forcing on atmospheric variability in the Northern Hemisphere provide further impetus for investigating the potential impact of Weddell Sea ice variability on local and remotely forced atmospheric circulation.

Against this background, we aimed to understand the role of sea-ice variability in the Weddell Sea in forcing atmospheric variability over the South Atlantic. For this purpose, we performed statistical analyses using observational data during the satellite era and conducted a series of CGCM experiments to verify the observational results.

\section{DATA, MODEL AND METHODOLOGY}

\subsection{Data and reanalysis}

A monthly mean gridded sea-ice dataset, NOAA Optimum Interpolation (OI) SST V2 (Reynolds et al. 2002), is used to analyze the interannual SIC variability. The dataset has a horizontal resolution of $1^{\circ} \times 1^{\circ}$ and covers the period 1982-2014, during the satellite era. The associated atmospheric variability is analyzed using the ERA interim monthly mean reanalysis (Dee et al. 2011) provided by the European Centre for Medium-Range Weather Forecasts (ECMWF). The atmospheric reanalysis dataset has a spectral T255 ( 60 km) resolution in the horizontal and 60 levels in the vertical, but here we use monthly outputs extrapolated onto a $1^{\circ} \times 1^{\circ}$ resolution horizontal grid (consistent with the horizontal resolution of the seaice dataset). For the above data and reanalysis, monthly anomalies were calculated with respect to the monthly climatology, after removing the linear monthly trends associated with climate change by using a least squares method.

\subsection{CGCM}

The statistical relationship observed between the sea ice and atmospheric variability is further inves- 
tigated by using the Scale Interaction ExperimentFrontier Research Center for Global Change 2 (SINTEX-F2; Masson et al. 2012) CGCM experiments. The SINTEX-F2 has an atmospheric component based on ECHAM5 (Roeckner et al. 2003), which was originally developed at the ECMWF, and has a parameterization package developed at the Max-Planck-Institute for Meteorology, Hamburg, Germany. The ECHAM5 has 31 levels in the vertical on a T106 Gaussian grid. The oceanic component of SINTEX-F2 is the Nucleus for European Modeling of the Ocean (NEMO; Madec 2008), which includes the Louvain-la-Neuve Sea Ice Model 2 (LIM2; Fichefet \& Morales Maqueda 1997) and has a $0.5^{\circ} \times 0.5^{\circ}$ horizontal resolution using an ORCA configuration (ORCA05) with 31 levels in the vertical. The atmospheric and oceanic fields are exchanged every $2 \mathrm{~h}$ by means of the Ocean Atmosphere Sea Ice Soil 3 (OASIS3) coupler (Valcke et al. 2004) with no flux correction. Previous studies have demonstrated that the SINTEX-F2 model reasonably simulates major climate modes (Masson et al. 2012) — such as ENSO and the South Atlantic and Indian Ocean Subtropical Dipoles (Morioka et al. 2014) - in terms of the spatial patterns and seasonality that are relevant to southern African climate variations.

In the control run (CTR) experiment, the SINTEX-F2 was integrated for 180 yr. Here and in all subsequent experiments, we used the same seasonal cycle in the solar radiation from year to year. Considering the time of oceanic adjustment to the interannual atmospheric forcing, we removed the first $30 \mathrm{yr}$ from the current analysis. To remove the influence of remote SST-driven teleconnection on the sea-ice variability in the Weddell Sea, we performed a series of sensitivity experiments. In the tropical Pacific (TP) experiment, the model SST in the tropical Pacific $\left(20^{\circ} \mathrm{S}-20^{\circ} \mathrm{N}\right)$ is strongly relaxed to the monthly climatology of the CTR experiment by adding negative feedback $(-2400 \mathrm{~W}$ $\mathrm{m}^{-2} \mathrm{~K}^{-1}$ ) of surface heat flux corresponding to $1 \mathrm{~d}$ restoring time for $50 \mathrm{~m}$ mixed-layer temperature (Morioka et al. 2014). In a similar manner, several SST nudging experiments are performed for the tropical oceans (TALL; $20^{\circ} \mathrm{S}-20^{\circ} \mathrm{N}$ ), the South Atlantic $\left(\mathrm{SAO}_{1} 10-55^{\circ} \mathrm{S}\right)$, the tropics and mid-latitudes $\left(\mathrm{TMD}_{i} 55^{\circ} \mathrm{S}-55^{\circ} \mathrm{N}\right)$, and all of the global oceans with SST climatology, including sea ice areas (CLM). We integrated all of the above sensitivity experiments over the same period as in the CTR experiment, and the monthly outputs of the last $150 \mathrm{yr}$ are analyzed.

\subsection{Methodology}

To investigate the potential impact of sea-ice variability on the overlying atmosphere, the atmospheric stability in the atmospheric boundary layer is calculated by using baroclinicity (Charney 1947, Eady 1949). The zonal $\left(B_{X}\right)$ and meridional $\left(B_{Y}\right)$ components of baroclinicity are simply measured by the meridional and zonal gradients of the potential air temperature $\theta$ as below,

$$
B_{X}=\frac{g}{N \theta} \frac{\partial \theta}{\partial y}, B_{Y}=\frac{g}{N \theta} \frac{\partial \theta}{\partial x}
$$

where $g$ is the gravitational acceleration and $N$ is the buoyancy frequency. For convenience of interpretation, the value for baroclinicity in the Southern Hemisphere is multiplied by -1 to make positive values correspond to a decrease in stability. Baroclinicity has been applied in past studies discussing the impact of mid-latitude SST fronts on atmospheric variability (e.g. Nakamura 2012).

The effects of the sea-ice variability on the downstream atmospheric circulation are investigated by calculating a wave activity flux associated with synoptic eddies, following Takaya \& Nakamura (1997, 2001). The wave activity flux provides a snapshot of the 3-dimensional propagation of the eddies in a phase-independent manner, and describes the propagation of stationary Rossby waves on a zonally varying basic flow in the upper troposphere. The formulation of the wave activity flux $\vec{W}_{s}$ is described by

$$
\vec{W}_{s}=\frac{p}{2|\vec{U}|}\left(\begin{array}{c}
U\left(\Psi_{X}^{\prime 2}-\Psi^{\prime} \Psi^{\prime}{ }_{X X}\right)+V\left(\Psi_{X}^{\prime}{ }_{X}^{\prime} \Psi_{Y}-\Psi^{\prime} \Psi_{X Y}^{\prime}\right) \\
U\left(\Psi_{X}^{\prime}{ }_{X} \Psi_{Y}^{\prime}-\Psi^{\prime} \Psi_{X Y}^{\prime}\right)+V\left(\Psi_{Y}^{\prime 2}-\Psi^{\prime} \Psi_{Y Y}^{\prime}\right) \\
\frac{f_{0}^{2}}{N^{2}}\left[U\left(\Psi_{X}^{\prime}{ }_{X} \Psi_{Z}^{\prime}{ }_{Z}-\Psi^{\prime} \Psi_{X Z}^{\prime}\right)+V\left(\Psi_{Y}^{\prime} \Psi_{Z}^{\prime}{ }_{Z}-\Psi^{\prime} \Psi_{Y Z}^{\prime}\right)\right]
\end{array}\right)
$$

where $p=$ (pressure / $1000 \mathrm{hPa}), \vec{U}=(U, V)$ is the horizontal wind, $\psi$ is the stream function, and $f_{0}$ is the Coriolis parameter. The subscripts $x, y$ and $z$ denote the derivatives to $x, y$ and $z$, respectively. Here, $\Psi^{\prime}$ indicates the deviation of stream function from the monthly climatology.

\section{OBSERVED ATMOSPHERE-SEA ICE RELATIONSHIP}

\subsection{Atmospheric impact on sea-ice variability}

To explore the potential impact of the interannual variability of Weddell Sea ice on the atmosphere, it 
may be useful to first consider the physical mechanisms behind the seasonal cycle in Weddell Sea SIC and sea-ice extent (SIE). The monthly climatology of the observed sea-ice extent in the Weddell Sea $\left(0-60^{\circ} \mathrm{W}\right)$ during the satellite period shows a distinct seasonal cycle, with a maximum in September and a minimum in February (Fig. 1). Considering a several month lag behind the seasonal cycle of solar insolation with a maximum in January and a minimum in June (figure not shown), the seasonal variation in the Weddell Sea SIE reflects a delayed response to atmospheric forcing. On the other hand, the monthly standard deviation of the Weddell Sea SIE shows 2 different peaks, one in April and another in December, both of which are significantly above 1 standard deviation (SD) of all monthly values. These 2 peaks correspond to the seasons in which the sea ice starts to grow and decay, respectively.

The 2 peaks (Fig. 1) observed in the monthly SD of the SIE in the Weddell Sea are more related to that of surface heat flux than that of surface horizontal winds (see Fig. S1a,b in the Supplement at www.int-res. com/articles/suppl/c074p171_supp.pdf), although the surface heat flux is not independent of surface winds due to the turbulent heat flux. In particular, the early summer (November-January: NDJ) peak in Fig. 1b shows a strong link with the variability in shortwave radiation (Fig. S1a), whereas the autumn peak (March-May) shows a relation to both sensible heat flux and longwave radiation. This suggests that different mechanisms may cause interannual variability in the sea-ice extent during these seasonal periods.

As discussed in previous studies (Meehl 1991, Meehl et al. 1998), the atmospheric pressure in the Southern Hemisphere shows a semiannual oscillation with peaks in March and September. The interannual variability in this semiannual atmospheric oscillation
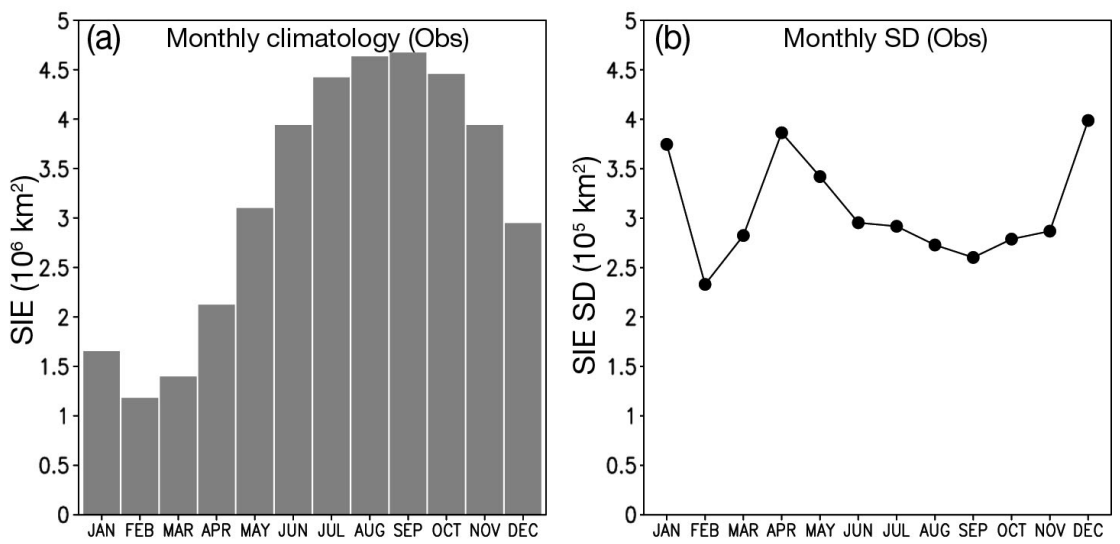

Fig. 1. Monthly (a) climatology and (b) standard deviation (SD) of the observed sea-ice extent (SIE) in the Weddell Sea may affect the austral autumn peak in the sea-ice variability. On the other hand, tropical forcing such as ENSO may contribute to the austral summer peak (e.g. Carleton 1988). However, the correlation coefficient between the Weddell Sea SIE and the NINO 3.4 index during NDJ is not very high, although it is statistically significant at 0.33 (Student's $t$-test with $95 \%$ confidence level). On the other hand, a recent study by Zhang et al. (2017) revealed different responses of Antarctic sea ice to the SAM depending on the seasons. We explored this possibility and found that the correlation between the Weddell Sea SIE and the SAM-related atmospheric circulation index (Gong \& Wang 1999) during NDJ (-0.26) is not statistically significant. Further research is required to physically understand those 2 peaks in the sea-ice variability of the Weddell Sea.

A spatial pattern of NDJ mean SIC shows that the sea ice covers most of the Weddell Sea region with its northernmost boundary at around $55^{\circ} \mathrm{S}$ (Fig. S2a in the Supplement). The surface area covered by the Antarctic sea ice in the Atlantic sector is much larger than that in the Indian Ocean sector. Because of the location at higher latitudes and lower surface temperature over Antarctica, skin temperature in the Weddell Sea is lower compared to all other Antarctic sea-ice areas (Fig. S2b). The associated sea-level pressure (SLP) exhibits minimum values over the Antarctic sea-ice area in an elongated zone between 60 and $70^{\circ} \mathrm{S}$ (Fig. S2c). Also, the Weddell Sea is located south of the entrance of a strong westerly jet positioned between 40 and $50^{\circ} \mathrm{S}$ (Fig. S2d). Since the westerly jet acts as a waveguide of stationary Rossby waves, any transient or synoptic disturbances generated north of the Weddell Sea region may have some effect on the downstream atmospheric circulation. The total cloud cover over the Weddell Sea region, most of which is comprised of low cloud cover, is as high as that over the Southern Ocean, indicating a potential impact of local sea ice, as well as the ocean on the formation of low cloud (Fig. S2e).

To describe the interannual sea-ice variability in the Weddell Sea, we calculated the SD of SIC anomalies during NDJ. In the Weddell Sea region $\left(0-60^{\circ} \mathrm{W}\right)$, Fig. 2a shows a significant variability in the band of $60-70^{\circ} \mathrm{S}$, but much less variability is observed in the higher latitudes $\left(70-80^{\circ} \mathrm{S}\right)$. To highlight the SIC variability in the Weddell Sea, we 
defined the Weddell Sea ice index as the SIC anomalies averaged over the area of $40-20^{\circ} \mathrm{W}$ and $60-$ $70^{\circ} \mathrm{S}$. We selected this area in order to avoid the negative influence of weak SIC variability in the higher latitudes $\left(70-80^{\circ} \mathrm{S}\right)$ on weakening the index.

Fig. $2 \mathrm{~b}$ shows time series of the standardized Weddell Sea ice index during November-January of 1982-2014. Here we defined the standardized Weddell Sea ice index as the Weddell Sea ice index divided by $1 \mathrm{SD}$ of the index during NDJ. The Weddell Sea ice index fluctuates from year to year, but there are very high sea-ice years $(1991,1994,2002$, 2011, 2013) in which the Weddell Sea ice index exceeds $0.8 \mathrm{SD}$. In a similar manner, very low sea-ice years $(1996,1998,1999,2001,2006,2010)$, with the index below $-0.8 \mathrm{SD}$, also occur. Three out of the 5 high SIC years (1991, 1994 and 2002) coincide with El Niño events, whereas only 1 year (2011) co-occurs with a La Niña event. On the other hand, 3 out of the 6 low SIC years (1998, 1999 and 2010) coincide with La Niña events, whereas only 1 year (2006) co-occurs with an El Niño event. Therefore, the relationship of
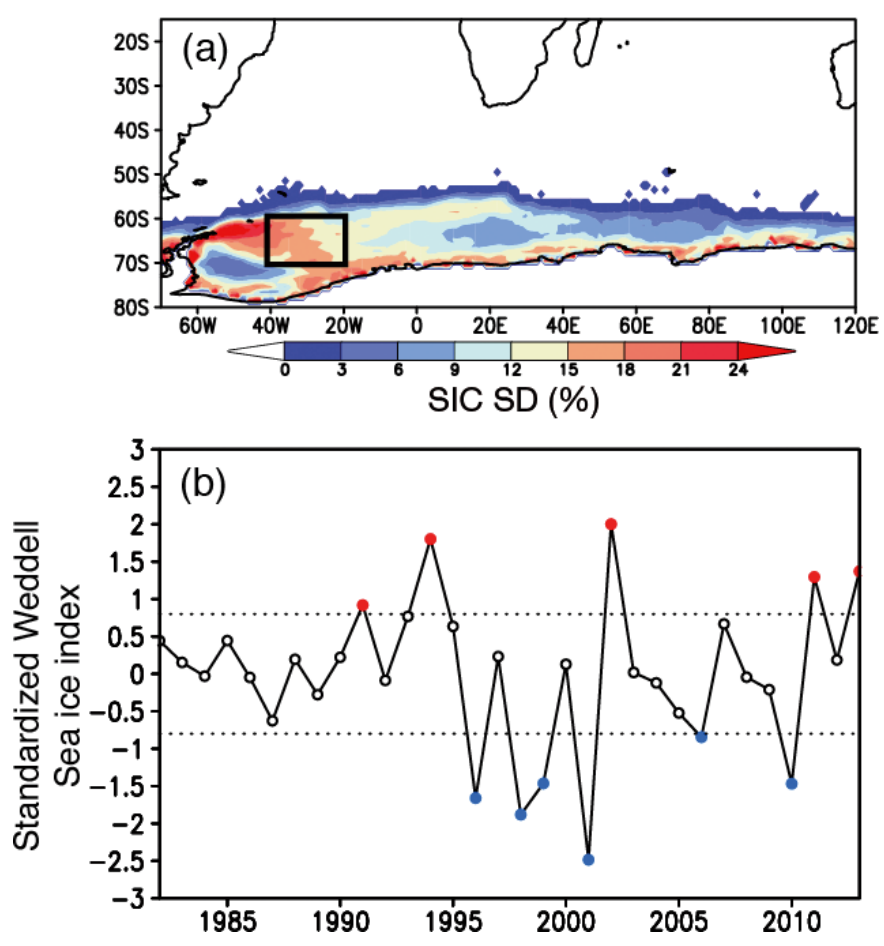

Fig. 2. (a) Spatial pattern of standard deviation (SD) of seaice concentration (SIC) observed during November-January (NDJ). The rectangular box corresponds to the region $\left(60-70^{\circ} \mathrm{S}, 20-40^{\circ} \mathrm{W}\right)$ in which the Weddell Sea ice index is defined. (b) Time series of standardized Weddell Sea ice index observed during NDJ of 1982-2014. The 2 dotted lines correspond to positive and negative $0.8 \mathrm{SD}$, respectively. The high and low Weddell Sea ice years are marked with red and blue closed circles, respectively the high SIC years with ENSO seems to be stronger than that of the low SIC years.

To investigate a statistical link between the Weddell Sea ice variability and the overlying atmosphere, we calculated monthly lead-lag correlation of atmospheric variables averaged in the area of the Weddell Sea highlighted in Fig. 2a (box) with regards to the NDJ Weddell Sea ice index (Fig. 3). The net surface heat flux shows a significant peak of negative correlation during NDJ, but the significant negative correlation starts to appear from the September-November (SON) season. This suggests that the net surface heat flux anomaly may play a role at least 2 mo before the NDJ SIC anomaly in the Weddell Sea. In particular, the decrease in the net surface heat flux is mostly attributed to an increase in the outgoing (i.e. reflected) solar radiation, which is related to an increase in the surface albedo due to the SIC increase. This is generally referred to as ice-albedo feedback (e.g. Curry et al. 1995), which significantly contributes to a rapid development of sea-ice variability. In addition to the surface heat flux, the zonal wind also shows a negative peak of correlation during SON, whereas the meridional wind has a positive peak of correlation during October-December (OND). This suggests that the southeasterly wind anomaly may also contribute to the higher sea-ice extent in the analysis region.

Another noteworthy result is obtained for skin temperature, which shows an increasingly negative correlation, statistically significant during NDJ, with a minimum in January (Fig. 3). This is a delayed response of the near-surface atmospheric temperature to the SIC increase, suggesting a potential sea-ice impact on the overlying atmosphere. The correlation coefficient between sea ice and skin temperatures during NDJ is statistically significant and high at -0.71 , which is much stronger than the correlation in the entire Antarctic region (-0.47). As summer progresses, sea-ice anomalies may have more influence on the atmosphere due to the increasing areas of open ocean and due to the changes in surface heat and moisture flux, as well as roughness gradients between the areas still covered by ice and those that have no ice.

The above correlation analysis evaluates the statistical relationship between the 2 variables, but does not explain causality. To further examine physical mechanisms behind the statistical relationship, we conducted composite analysis of the atmospheric circulation and thermodynamic anomalies that occur during the low ice years for the Weddell Sea. We limit our discussion to the case of low SIC years, because 


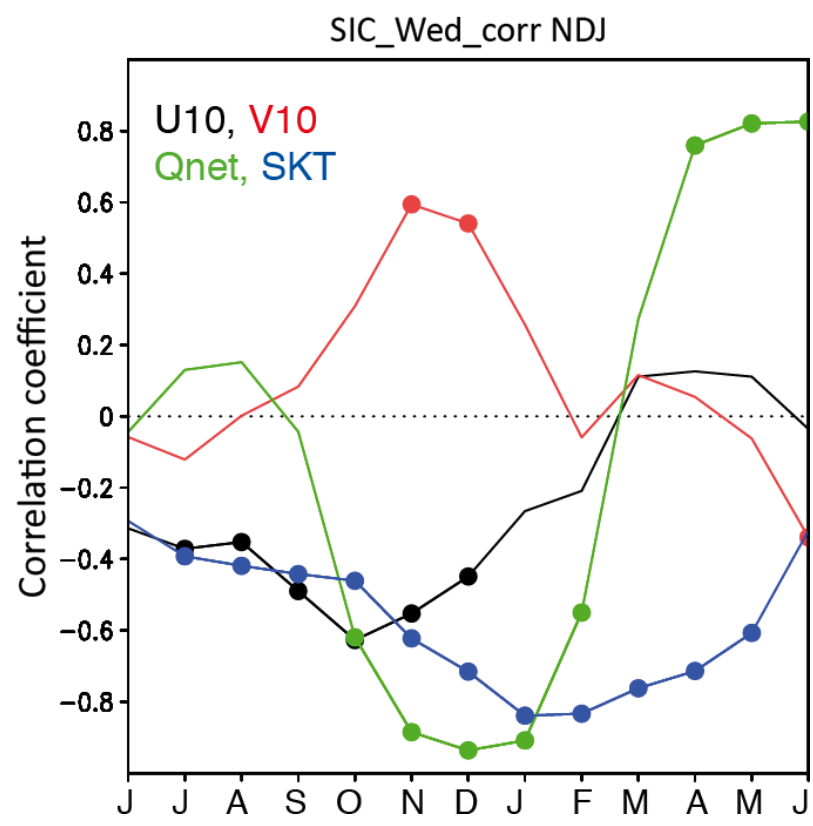

Fig. 3. Lead-lag correlation coefficients between the NovemberJanuary (NDJ) observed sea-ice concentration (SIC) averaged in the Weddell Sea (SIC_Wed) and other atmospheric variables. Correlation coefficients for atmospheric variables were calculated by using the spatially averaged anomalies over the Weddell Sea as indicated by the box in Fig. 2. Note that the 3 mo average values are used for each month of the atmospheric variables (e.g. 'D' corresponds to NDJ). The correlation coefficients for the zonal (black) and meridional (red) wind speeds at $10 \mathrm{~m}$, surface heat flux (green), and skin temperature (blue) are shown. Positive net surface heat flux indicates warming of the ocean. Correlation coefficients significant at the $95 \%$ confidence level by using Student's $t$-test are marked with closed circles

similar but opposite results are obtained for the high SIC years. The sea ice and atmospheric anomalies significantly decay after the peak of NDJ, so here we examine the development and peak phase of the seaice anomaly during OND and NDJ, respectively.

Composite anomalies of SIC, surface heat flux and horizontal wind at $10 \mathrm{~m}$ (Fig. 4) represent the same relationship derived from the lead-lag correlation analysis (Fig. 3) earlier. Here we employed the false discovery rate (FDR) method to check statistical significance of composite field anomalies (see Eq. 3 in Wilks 2016). Since approximately correct results can be achieved by choosing the FDR test level twice as large as the global test level for data grids exhibiting moderate to strong spatial correlation (see Fig. 4 in Wilks 2016), we used an FDR test level of 0.10. The significant reduction in the Weddell Sea ice during NDJ may be related to an increase in the net surface heat flux (shortwave radiation) and northwesterly wind anomalies starting from OND. This implies that the northwesterly wind anomalies push the sea ice southeastward, thereby rendering large areas of sea ice-free, which results in lowering the surface albedo and increasing the heat flux due to shortwave radiation. The cyclonic wind anomalies east of the Antarctic Peninsula (Fig. 4) also tend to reduce the sea ice, presumably by generating Ekman upwelling to warm the sea ice from the bottom. The oceanic process may contribute to the sea-ice melt, but the seaice response to this oceanic forcing is slower than that to the atmospheric forcing (Ferreira et al. 2015). Therefore, we conclude that the Weddell Sea ice variability during NDJ may be driven by atmospheric forcing, consistent with the findings of a number of studies cited in the Introduction.

\subsection{Sea ice to atmosphere feedback}

The observed atmospheric anomalies in the Weddell Sea during the low SIC years tend to persist for more than one season. It is reasonable to attribute the persistence of the composite atmospheric anomalies to remote forcing such as ENSO (Carleton 1988, Yuan \& Martinson 2000) and the SAM (Liu et al. 2004, Udagawa et al. 2009, Murphy et al. 2014), but we cannot rule out local air-sea-ice interactions associated with the Weddell Sea ice variability. The reduction in the sea ice enables the ocean to directly influence the lower atmosphere, and in particular skin temperature. Composite anomalies of skin temperature during OND (Fig. 5a) show significantly warm anomalies (up to $1.5 \mathrm{~K}$ ) over the region where the sea-ice reduction is observed. The associated SLP anomaly shows an anticyclonic circulation anomaly to the northeast of the warm temperature anomaly (Fig. 5b). The anticyclonic circulation anomaly is strongly associated with the cyclonic circulation anomaly around the Antarctic Peninsula. Although the northwesterly wind anomaly contributes to more advection of warm air from the lower latitudes, the skin temperature anomaly is spatially limited over the sea-ice reduction area, indicating the dominant role of the ocean in driving the temperature anomaly. The skin temperature anomaly becomes relatively weak during the peak of the Weddell Sea ice anomaly, i.e. in NDJ (Fig. 5c). The anticyclonic circulation anomaly also weakens (Fig. 5d) in association with the skin temperature anomaly. A similar warming tendency is also observed for the potential temperature anomaly at $925 \mathrm{hPa}$ (figure not shown). This suggests that the atmospheric temperature anomaly associated with the sea-ice anomaly peaks higher in the overlying atmosphere as summer progresses, in 

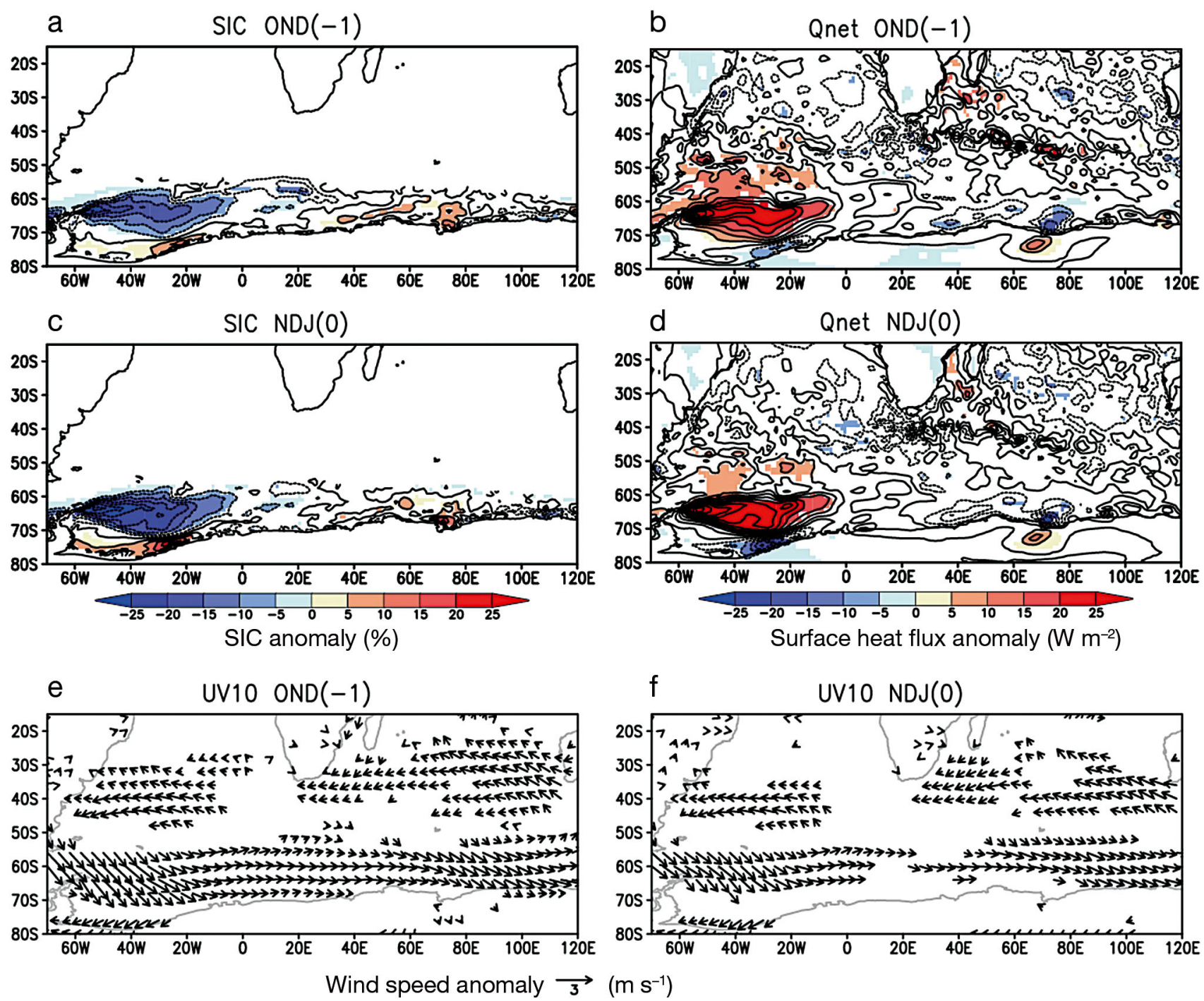

Fig. 4. Composite anomalies of $(\mathrm{a}, \mathrm{c})$ observed sea-ice concentration (SIC), (b,d) surface heat flux and (e,f) zonal and meridional winds at $10 \mathrm{~m}$ during $(\mathrm{a}, \mathrm{b}, \mathrm{e})$ October-December (OND) and $(\mathrm{c}, \mathrm{d}, \mathrm{f})$ November-January (NDJ) of the low Weddell Sea ice years. $(-1)$ and (0) after OND and NDJ: the previous and simultaneous years, respectively, of the composite years. Positive net surface heat flux indicates warming of the ocean. Anomalies with $\mathrm{p}<0.10$ using the false discovery rate method are colored (a-d) and shown by arrows $(\mathrm{e}, \mathrm{f})$. Non-significant values are not shaded (blank areas)

part because the boundary layer depth grows over summer.

In the mid- to high latitudes, changes in surface temperature may affect atmospheric circulation through changes in near-surface stability, i.e. baroclinicity, which is usually measured by the horizontal gradient in potential temperature (e.g. Nakamura 2012). The anomalous increase in skin temperature associated with the Weddell Sea ice reduction during OND is likely to weaken the meridional temperature gradient in the atmospheric boundary layer north of the Weddell Sea at around $60^{\circ} \mathrm{S}$. This can be seen in the meridional component of baroclinicity (Fig. 6) with a significant negative anomaly north of the Weddell Sea at around $60^{\circ} \mathrm{S}$. This suggests that the near-surface atmosphere becomes more stable than normal. On the other hand, composite anomalies of the meridional component of baroclinicity during NDJ are not as strong as those during OND. As expected from the significantly warmer temperature anomaly, the sea-ice reduction during OND may have a stronger effect on the near-surface atmospheric stability to the north.

To investigate up to which vertical level the sea-ice reduction could affect the synoptic atmospheric variability, the vertical component of the wave activity flux was calculated at each model level and displayed along with the composite anomaly of geopotential height. The wave activity flux during OND (Fig. 7) shows upward wave propagation from the 

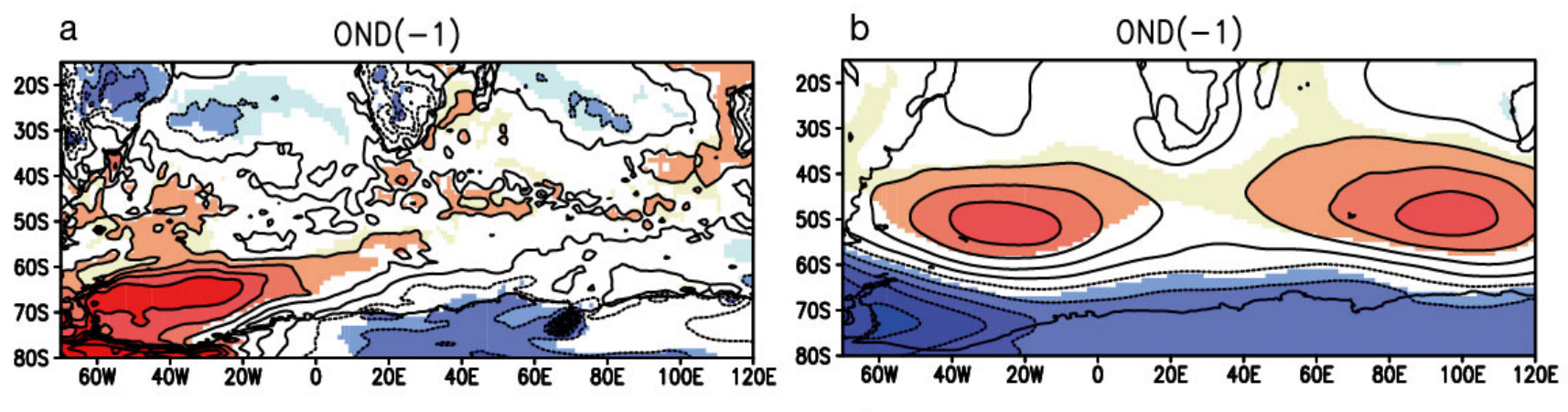

C

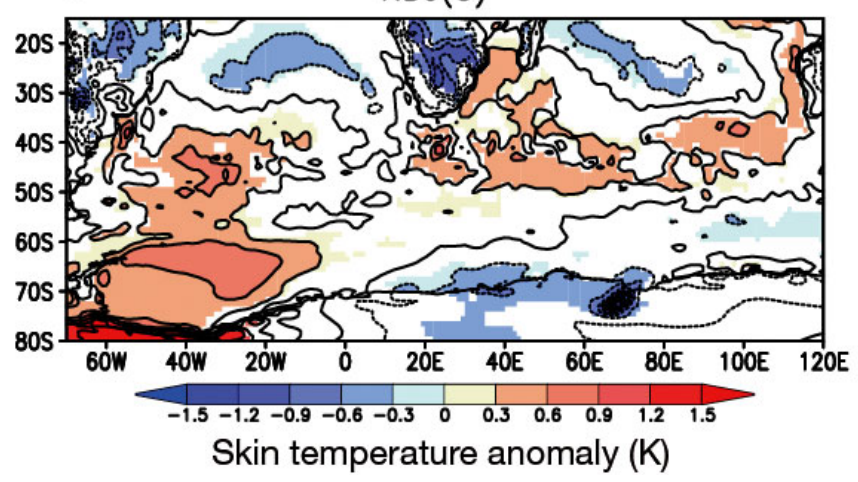

d

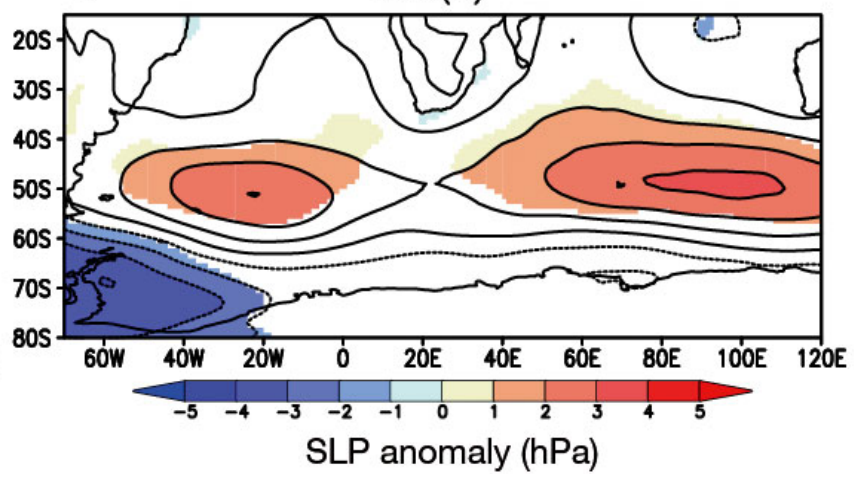

Fig. 5. Same as in Fig. 4, but for $(\mathrm{a}, \mathrm{c})$ observed skin temperature and $(\mathrm{b}, \mathrm{d})$ sea-level pressure (SLP)

lower troposphere at $850 \mathrm{hPa}$ to the middle troposphere at $500 \mathrm{hPa}$ northwest of the Weddell Sea, where the negative anomalies in the meridional component of baroclinicity are observed (Fig. 6). However, the vertical wave propagation is not clearly observed above the middle troposphere (figure not shown). This indicates that the effect of sea-ice variability on atmospheric variability is limited to the lower troposphere. Vertical wave propagation is also detected during NDJ, but its amplitude is weaker than that in OND.

In order to further inspect how vertical wave propagation, from the low troposphere to the middle troposphere, affects the downstream atmospheric variability, the horizontal component of wave activity flux was calculated at each level together with composite anomaly of geopotential height (Fig. 8). The wave activity flux at $500 \mathrm{hPa}$ during OND (Fig. 8a) shows northeastward wave propagation from the negative geopotential height anomaly around the Antarctic Peninsula to the positive anomaly (20$40^{\circ} \mathrm{W}, 45-55^{\circ} \mathrm{S}$ ) north of the Weddell Sea ice reduction area where the vertical wave propagation is observed. The negative anomaly is also associated with Rossby wave propagation from a positive anomaly in the South Pacific and a negative anomaly east of New Zealand, possibly related to the PSA telecon-
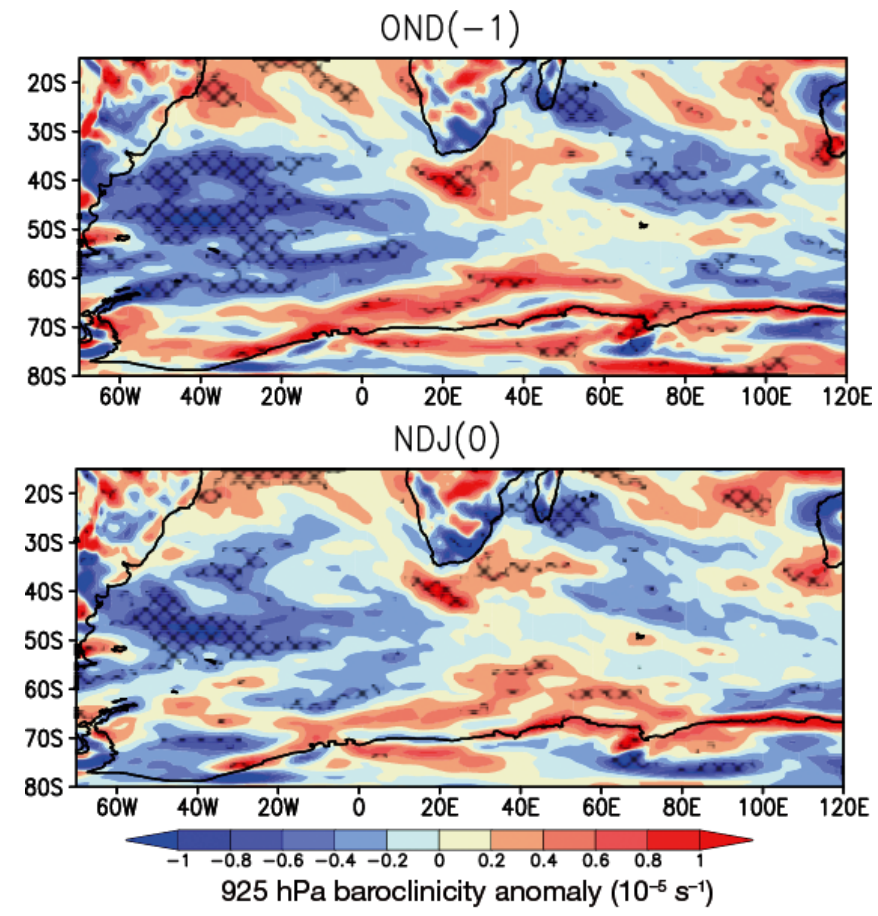

Fig. 6. Same as in Fig. 4, but for the observed meridional component of baroclinicity at $925 \mathrm{hPa}$. For convenience of interpretation, the value for baroclinicity is multiplied by -1 to make the positive value correspond to a decrease in stability. Anomalies with $\mathrm{p}<0.10$ using the false discovery rate method are cross-hatched 

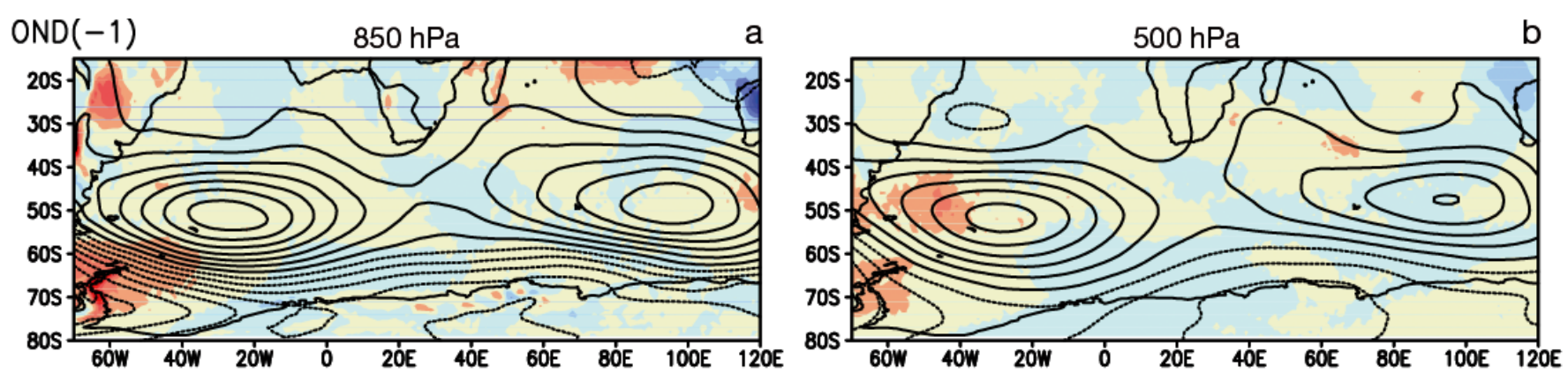

$\operatorname{NDJ}(0)$

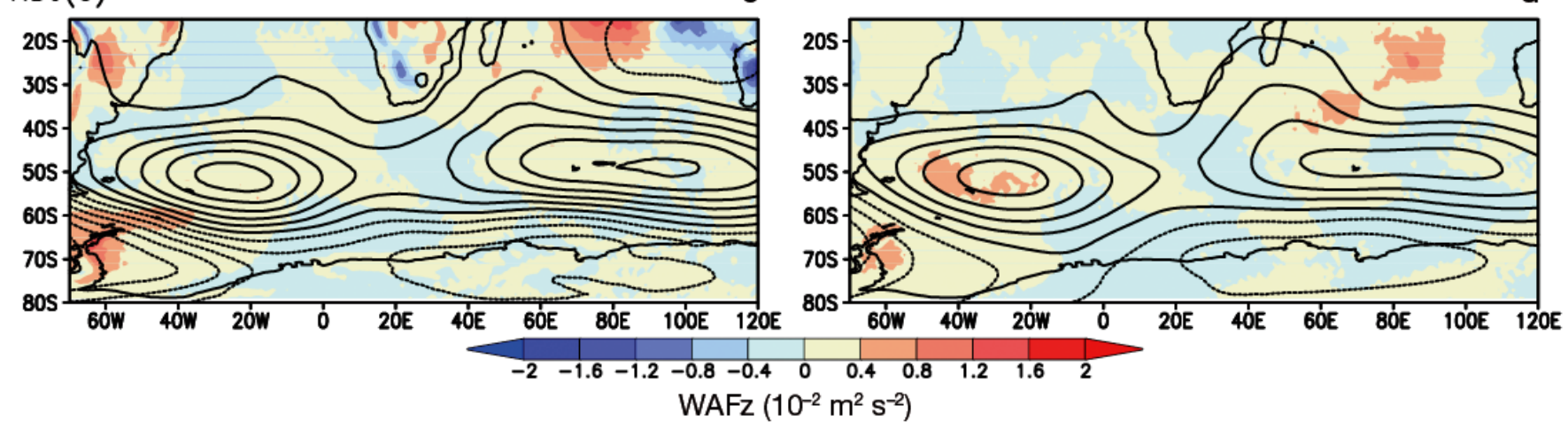

Fig. 7. Same as in Fig. 4, but for (a,c) observed geopotential height at $850 \mathrm{hPa}$ (contour interval is $10 \mathrm{~m}$ ) and the vertical component of the wave activity flux (WAFz) at $850 \mathrm{hPa}$ (colors), and (b,d) geopotential height at $500 \mathrm{hPa}$ (contour interval is $10 \mathrm{~m}$ ) and the $\mathrm{WAF} z$ at $500 \mathrm{hPa}$ (colors)

nection from the tropical Pacific (figure not shown). In addition to this remote process, atmospheric eddies induced by the sea-ice reduction may also contribute to the positive geopotential height anomaly in the South Atlantic locally through vertical and horizontal wave propagation. A similar wave propagation is observed during NDJ (Fig. 8c,d), but the effect of the vertical wave propagation is relatively weak and limited below the middle troposphere (Fig. $7 \mathrm{c}, \mathrm{d}$ ).

\section{SIMULATED SEA-ICE VARIABILITY AND ITS IMPACT ON ATMOSPHERIC VARIABILITY}

Long-term output of CGCM simulations involving a dynamical sea-ice model may be helpful to further explore the observed relationships with atmospheric variability (Kay et al. 2014), because the observational data record of the Antarctic SIC is relatively short and insufficient to conclusively establish a statistical link between sea ice and atmospheric variability. The 150 yr output from the control run (CTR) experiment with the SINTEX-F2 model (Fig. S3 in the Supplement) shows that the model underestimates the monthly climatologies of the observed seaice extent in the Weddell Sea, but it captures the observed seasonal cycle with a peak in September and a minimum in February. The relatively low seaice extent in the CTR experiment can be seen from the spatial distribution of lower-than-observed SIC (Fig. S4a in the Supplement). This is associated with warmer surface air temperature (Fig. S4b), higher SLP (Fig. S4c), and reduced total cloud cover (Fig. $\mathrm{S} 4 \mathrm{e})$ over the Weddell Sea region, which indicates that the stronger-than-observed incoming solar radiation contributes to the relatively low sea-ice extent in the model. The monthly SD of the sea-ice extent in the Weddell Sea (Fig. S3) shows that the model simulates 2 different peaks as observed, although the exact timing of the peaks, particularly the April peak, is off.

Following the observational analysis in Section 3, we defined the high and low Weddell Sea ice years as years when the simulated SIC anomaly during NDJ in the analysis region $\left(20-40^{\circ} \mathrm{W}, 60-70^{\circ} \mathrm{S}\right)$ exceeds, in absolute value, an SD of 0.8 . This leads to 29 and 32 events for the high and low SIC years, respectively. Composite SIC anomalies in the CTR experiment (Fig. 9) show that the SIC reduction in the Weddell Sea is well simulated during the development phase of the SIC anomaly, i.e. in OND, but its extent is slightly underestimated compared to that in the observation, partly due to a larger sample size. In the following month, NDJ, the simulated SIC anomaly 

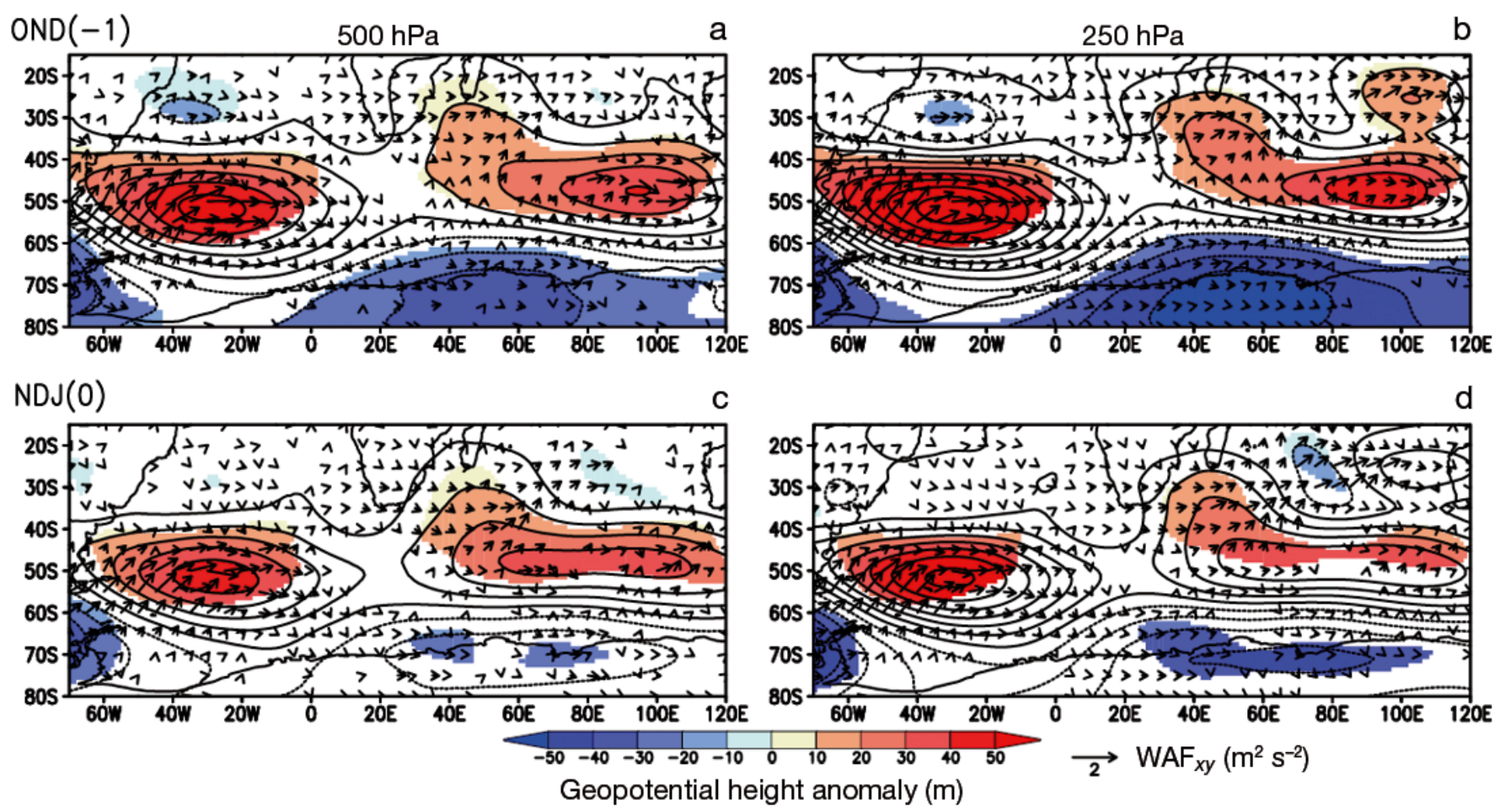

Fig. 8. Same as in Fig. 4, but for $(\mathrm{a}, \mathrm{c})$ observed geopotential height at $500 \mathrm{hPa}$ (contours and colors, m) and the horizontal component of the wave activity flux (WAFXY) at $500 \mathrm{hPa}$ (arrows), and (b,d) geopotential height at $250 \mathrm{hPa}$ (contours and colors, m) and the WAFxy at $250 \mathrm{hPa}$ (arrows). Geopotential height anomalies with $\mathrm{p}<0.10$ using the false discovery rate method are colored, and non-significant values are not shaded (blank areas)

becomes weaker than that in OND (figure not shown) as expected from the results of the monthly SD of sea-ice extent in Fig. S3.

To highlight the potential impact of the Weddell Sea ice variability onto the overlying atmosphere, we made a multiple comparison of surface atmospheric and sea-ice variables through several sensitivity experiments. For all other sensitivity experiments, the criteria to define the high and low Weddell Sea ice years are kept the same as used in the CTR experiment. Composite SIC anomalies during OND in the tropical Pacific (TP) and all tropical (TALL) experiments show a significant decrease in the SIC with a similar amplitude and spatial pattern of the SIC anomalies in the CTR experiment (Fig. 9). This suggests an important role of mid- to high latitude SST anomalies in the Weddell Sea ice variability and also that tropical forcing may not play an important role.

The SIC anomalies in the South Atlantic (SAO) experiment also resemble those in the CTR experiment, indicating that the local SST anomalies in the South Atlantic have a weaker impact on Weddell Sea ice variability compared to the SST anomalies outside the South Atlantic. Furthermore, the tropical and midlatitude (TMD) experiment shows a significant decrease in sea ice, indicating the importance of the high latitude SST variability. On the other hand, the global ocean climatology (CLM) experiment represents much weaker SIC anomalies in contrast with the other 4 sensitivity experiments. Since the interannual SST variability is globally suppressed by the monthly climatology, the difference between the CLM and other experiments confirms the notion that the SST variability in the high latitudes plays an important role in the local air-sea-ice interaction around the Weddell Sea.

The atmospheric response to sea-ice reduction shows similar variation across the different experiments performed. Composite anomalies of skin temperature during OND in the CTR experiment produce a warmer-than-normal condition over the seaice reduction area (Fig. 10). The warm anomalies in the skin temperature are also simulated with comparable amplitude in the TP, TALL, SAO and TMD experiments, but the CLM experiment only shows a slight increase in the skin temperature which is spatially confined from south of $70^{\circ} \mathrm{S}$ to Antarctica. Given the weaker SIC anomalies in the CLM experiment (Fig. 9), it is reasonable to note the weaker response of atmospheric temperature to the SIC anomalies compared to those in the other experiments.

Similar behavior in the atmospheric response is also obtained in terms of circulation anomalies. Com- 

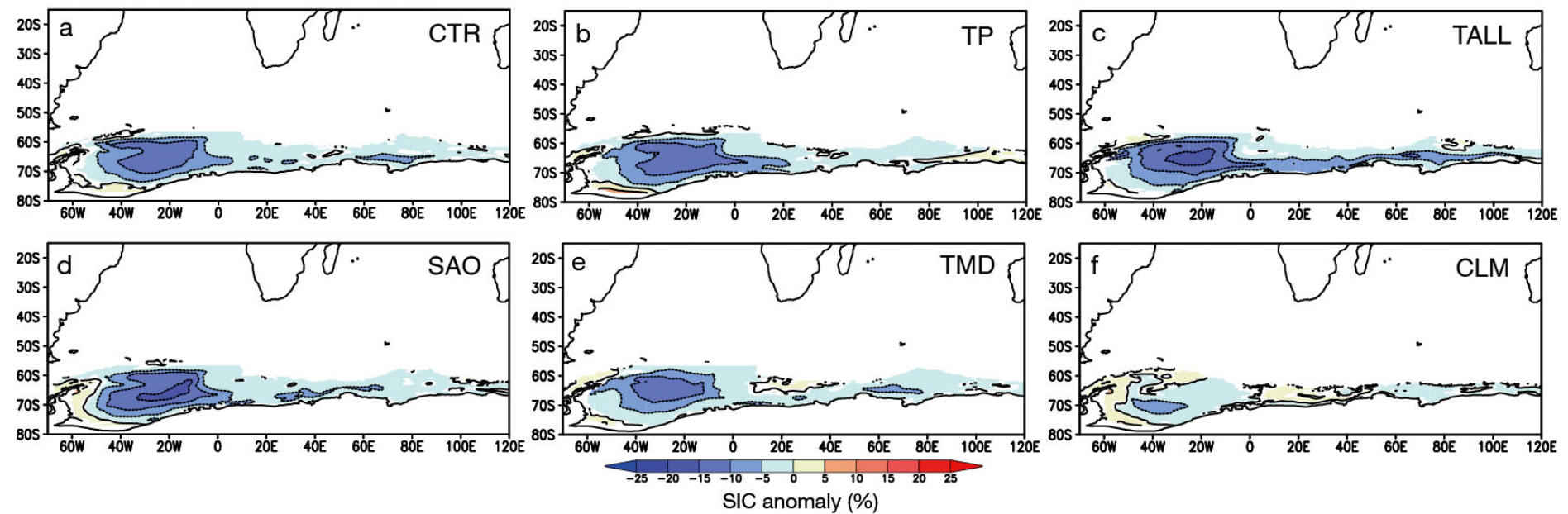

SIC anomaly (\%)

Fig. 9. Composite anomalies of the simulated sea-ice concentration (SIC, \%) during October-December (OND) of low Weddell Sea ice years for the (a) control run (CTR), (b) tropical Pacific (TP), (c) all tropical (TALL), (d) South Atlantic (SAO), (e) tropical and mid-latitudes (TMD) and (f) global ocean climatology (CLM) experiments. Anomalies with $\mathrm{p}<0.10$ using the false discovery rate method are colored, and non-significant values are not shaded (blank areas)

posite SLP anomalies during OND in the CTR experiment, although the amplitude is almost half as much as the observation (Fig. 5), reasonably represent the observed anticyclonic circulation anomalies in the South Atlantic, but fail in representing those in the southern Indian Ocean (Fig. 11). In particular, the northwest-southeast tilted structure of the positive SLP anomalies in the South Atlantic provides northwesterly wind anomalies over the Weddell Sea that generally act to reduce the sea-ice extent. As observed in the atmospheric reanalysis, the warmer skin temperature associated with the sea-ice decrease is likely to reduce the meridional temperature gradient to the north. This can contribute to the high- pressure anomalies by enhancing the near-surface atmospheric stability to the north of the low sea-ice anomaly.

The northwest-southeast tilted pattern of the positive SLP anomalies is also simulated in the TP, TALL, SAO and TMD experiments, but the CLM experiment only shows a strong dominance of the positive SLP anomalies over Antarctica. Rather, it is associated with the negative SLP anomalies in the lower latitudes, indicating an existence of strong atmospheric internal variability accompanied by a negative polarity of the SAM. The difference in the SLP anomalies between the CLM and other experiments suggests that the feedback between sea ice and
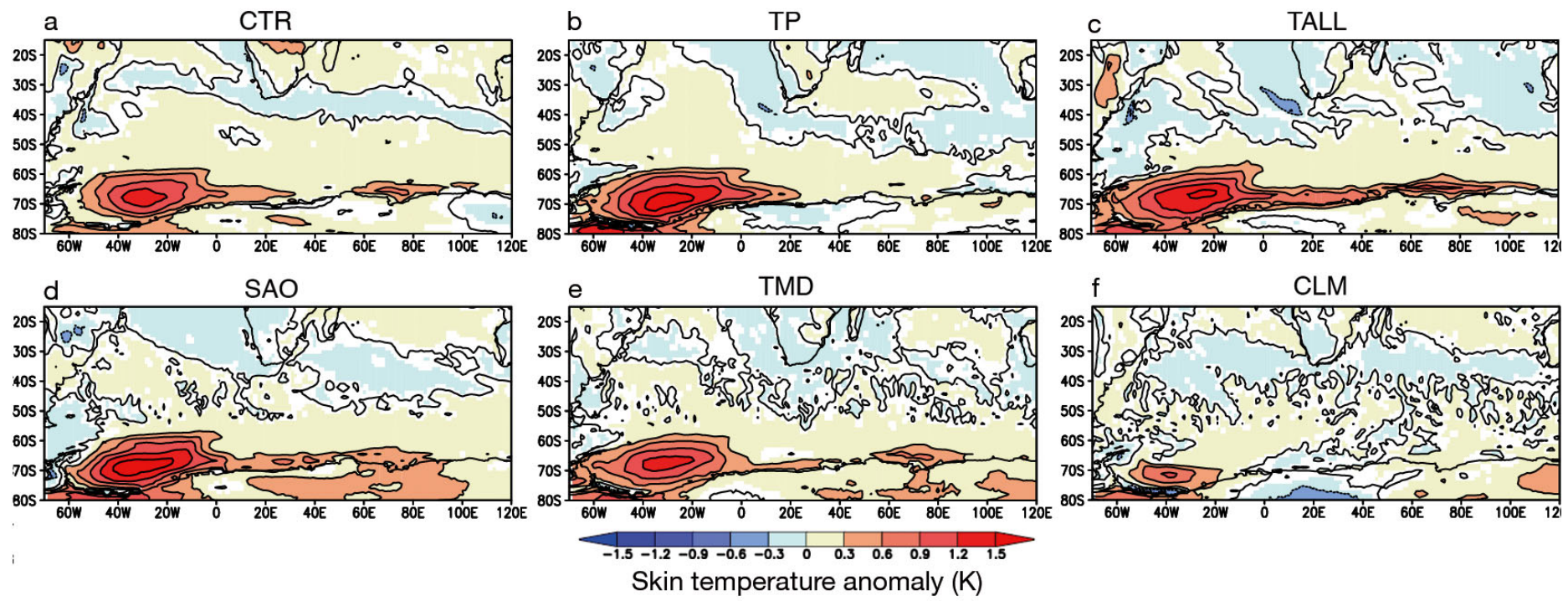

Fig. 10. Same as in Fig. 9, but for simulated skin temperature anomalies (K) 

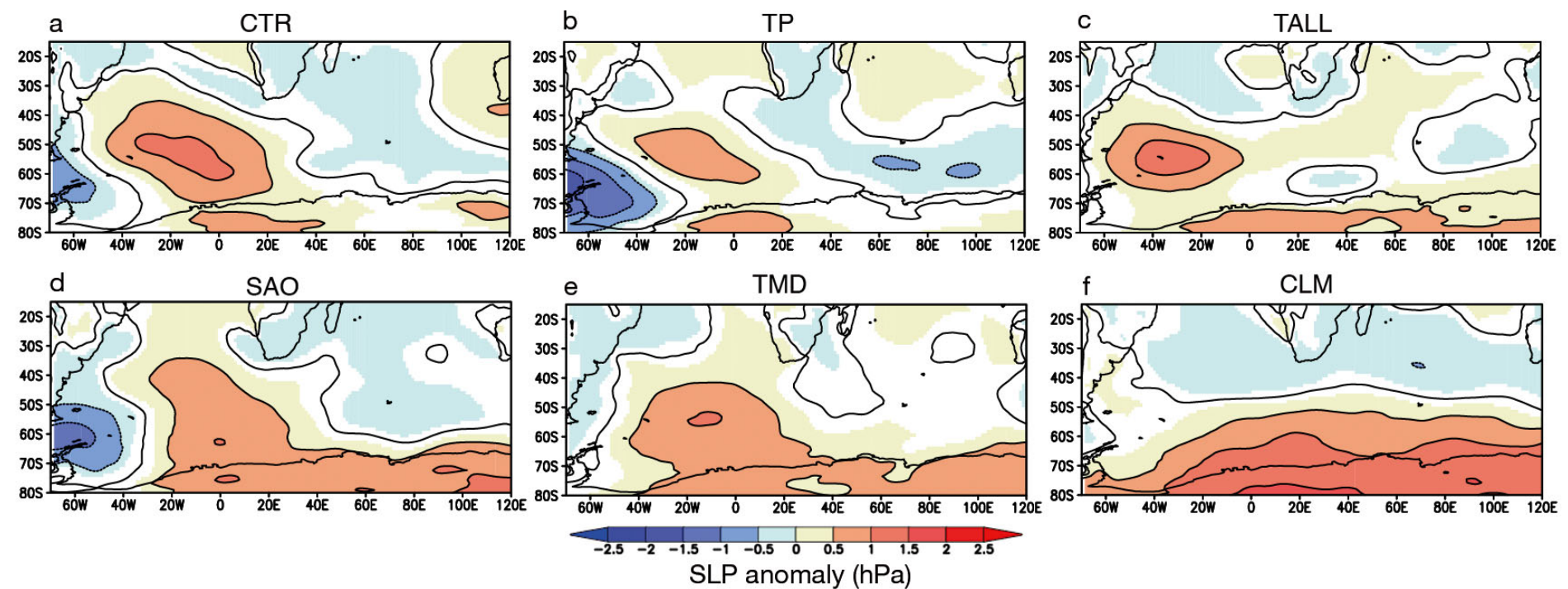

Fig. 11. Same as in Fig. 9, but for simulated sea-level pressure (SLP) anomalies (hPa)

atmosphere may be weak under the existence of atmospheric internal variability.

To further look at local influences on atmospheric variability near the Weddell Sea, the geopotential height anomalies and the wave activity flux at $250 \mathrm{hPa}$ are calculated and shown in Fig. 12. The CTR experiment shows the strong association between the positive anomalies north of the Weddell Sea and the negative anomalies around the Antarctic Peninsula. This is consistent with the circulation anomalies observed in the reanalysis data.

The negative anomalies are also associated with Rossby wave propagation from the positive anomalies in the South Pacific (figure not shown), but the positive anomalies are not as strong as the negative anomalies around the Antarctic Peninsula, indicating a weak relation with the Antarctic Dipole (Yuan \& Martinson 2001). The negative anomalies around the Antarctic Peninsula in the TP, TALL and TMD experiments are also found in association with weak positive anomalies in the South Pacific (figure not shown). However, these represent circumpolar patterns of positive and negative anomalies in the midto high latitudes, suggesting the importance of the remote effects as well as local influences on the atmospheric variability near the Weddell Sea. Since there is no tropical forcing in the Pacific and/or other basins in these experiments, the atmospheric circulation anomalies may be internally generated in the mid-tohigh latitude variability. On the other hand, the CLM
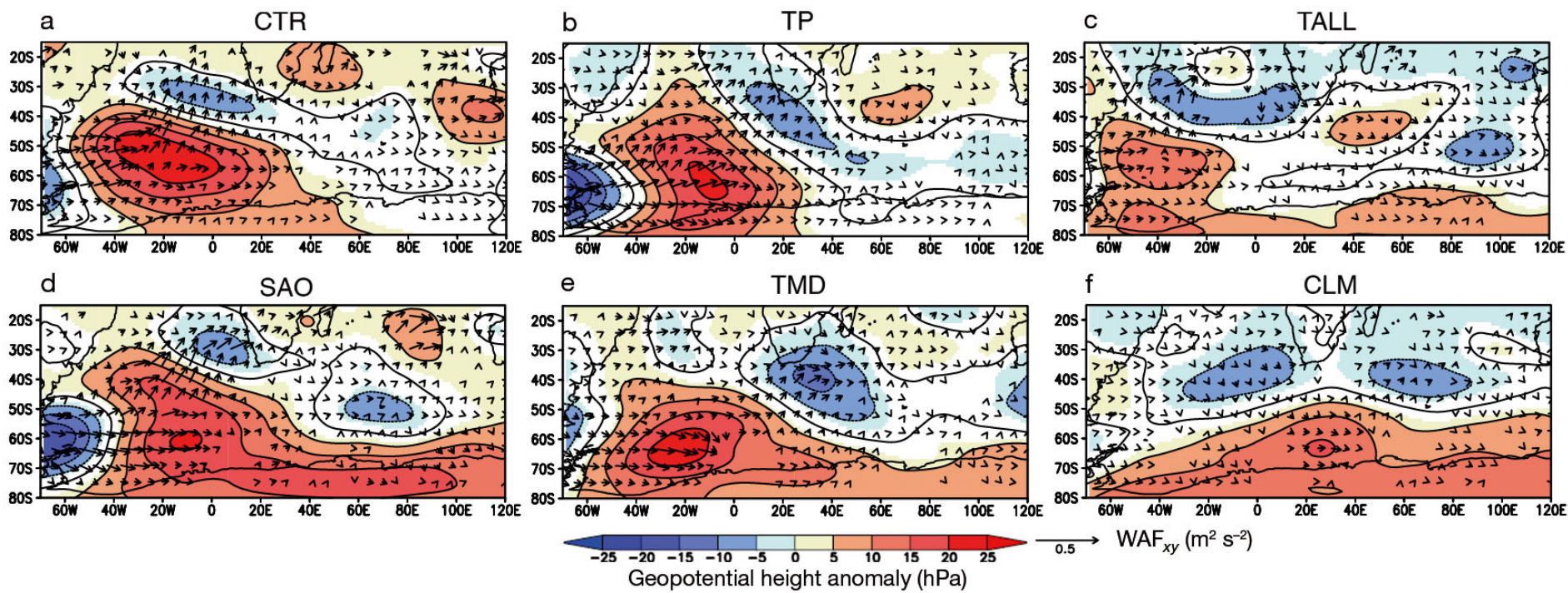

Fig. 12. Same as in Fig. 9, but for simulated geopotential height anomalies (contours and colors) and wave activity flux (WAFxy, arrows) at $250 \mathrm{hPa}$. Geopotential height anomalies with $\mathrm{p}<0.10$ using the false discovery rate method are shown, and non-significant values are not shaded (blank areas) 
experiment shows a strong dominance of the negative SAM in the Southern Hemisphere, as seen in Fig. 12.

\section{SUMMARY AND DISCUSSION}

The interannual sea-ice variability in the Weddell Sea during early austral summer, and its potential role in the South Atlantic atmospheric variability, are examined by performing observation-based data analysis and CGCM experiments. The analysis of the observational and reanalysis data during the satellite period reveals that the interannual sea-ice variability in the Weddell Sea is significantly linked to the overlying atmospheric variability. The decrease in SIC in the Weddell Sea at interannual timescales is strongly associated with a decrease in outgoing solar radiation and the anomalous northwesterly winds. The sea-ice reduction, in turn, warms the surface temperature to above normal, and is likely to weaken the meridional temperature gradient to the north of the Weddell Sea. This leads to higher atmospheric stability in the atmospheric boundary layer north of the Weddell Sea and contributes to sustaining an anticyclonic circulation anomaly in the lower troposphere.

This intriguing link between the variability of sea ice and atmospheric variability in the Weddell Sea is to some extent represented in the long-term simulation of the CGCM experiment. Although the simulated amplitude in the sea-ice extent is weaker than observed, the simulations are useful to investigate the nature of air-sea-ice interactions through a series of sensitivity experiments, e.g. by suppressing the interannual variability of SST in the tropics and mid-latitudes. These results suggest that air-sea-ice interactions in the high latitudes play a crucial role in the Weddell Sea ice variability, and hence the atmospheric variability of the South Atlantic.

The impacts of ENSO and the SAM on the summertime sea-ice variability in the Weddell Sea, and also atmospheric variability in the South Atlantic, have been widely discussed in the literature (Carleton 1988, Gillett et al. 2006, Murphy et al. 2014), but few studies (Venegas \& Drinkwater 2001) have examined a potential role of the Weddell Sea ice variability in the overlying atmospheric variability. Therefore, this study provides new insight into the potential role of the summertime Weddell Sea ice variability in the atmospheric variability of the South Atlantic. The interannual sea-ice variability in the Weddell Sea should be taken into account for the realistic simulation and skillful prediction of the atmospheric variability in the South Atlantic.
However, the CGCM used in this study underestimates the seasonal and interannual variations in the observed sea-ice extent. These biases may be related to a warmer skin temperature bias associated with stronger solar radiation over the Antarctic sea ice region, but identifying the cause of the warm bias is beyond the scope of this study. In addition, the atmospheric teleconnection from the South Atlantic to the southern Indian Ocean in the observation is not well simulated in the model experiment. Since the atmospheric teleconnection has potential impacts on southern African climate through atmospheric variability in the southern Indian Ocean (Fauchereau et al. 2003), the significant bias in the sea-ice simulation and atmospheric circulation anomalies should be examined and improved in future model development studies.

Acknowledgements. The SINTEX-F2 was run on the Scalar Parallel Computer System and the Earth Simulator at the Japan Agency for Marine Earth Science and Technology (JAMSTEC). We thank Dr. Oliver Frauenfeld and 2 anonymous reviewers for their constructive comments that improved the original manuscript. The present research is supported by JSPS KAKENHI Grant 15K17768, the Japan Science and Technology Agency/Japan Agency for Medical Research and Development through the Science and Technology Research Partnership for Sustainable Development (SATREPS), and the Applied Centre for Climate and Earth System Studies (ACCESS) in South Africa.

\section{LITERATURE CITED}

Carleton AM (1988) Sea ice-atmosphere signal of the Southern Oscillation in the Weddell Sea, Antarctica. J Clim 1: 379-388

Charney JG (1947) The dynamics of long waves in a baroclinic westerly current. J Meteorol 4:136-162

Colberg FC, Reason JC, Rodgers K (2004) South Atlantic response to El Niño-Southern Oscillation induced climate variability in an ocean general circulation model. J Geophys Res 109:C12015

* Curry JA, Schramm JL, Ebert EE (1995) Sea ice-albedo climate feedback mechanism. J Clim 8:240-247

Dee DP, Uppala SM, Simmons AJ, Berrisford P and others (2011) The ERA-Interim reanalysis: configuration and performance of the data assimilation system. QJR Meteorol Soc 137:553-597

Doyle ME, Barros VR (2002) Midsummer low-level circulation and precipitation in subtropical South America and related sea surface temperature anomalies in the South Atlantic. J Clim 15:3394-3410

Eady ET (1949) Long waves and cyclone waves. Tellus 1: 33-52

Fauchereau N, Trzaska S, Richard Y, Roucou P, Camberlin P (2003) Sea-surface temperature co-variability in the Southern Atlantic and Indian Oceans and its connections with the atmospheric circulation in the Southern Hemisphere. Int J Climatol 23:663-677

* Ferreira D, Marshall J, Bitz CM, Solomon S, Plumb A (2015) Antarctic Ocean and sea ice response to ozone depletion: a two-time-scale problem. J Clim 28:1206-1226 
Fichefet T, Morales Maqueda MA (1997) Sensitivity of a global sea ice model to the treatment of ice thermodynamics and dynamics. J Geophys Res 102:12609-12646

Gillett NP, Kell TD, Jones PD (2006) Regional climate impacts of the Southern Annular Mode. Geophys Res Lett 33: L23704

Gong D, Wang S (1999) Definition of Antarctic oscillation index. Geophys Res Lett 26:459-462

Honda M, Inoue J, Yamane S (2009) Influence of low Arctic sea-ice minima on anomalously cold Eurasian winters. Geophys Res Lett 36:L08707

Hudson DA, Hewitson BC (2001) The atmospheric response to a reduction in summer Antarctic sea-ice extent. Clim Res 16:79-99

Inoue J, Hori ME, Takaya K (2012) The role of Barents Sea ice in the wintertime cyclone track and emergence of a warm-Arctic cold-Siberian anomaly. J Clim 25:2561-2568

Irving D, Simmonds I (2016) A new method for identifying the Pacific-South American pattern and its influence on regional climate variability. J Clim 29:6109-6125

Kay JE, Medeiros B, Hwang YT, Gettelman A, Perket J, Flanner MG (2014) Processes controlling Southern Ocean shortwave climate feedbacks in CESM. Geophys Res Lett 41:616-622

Liu J, Curry JA, Martinson DG (2004) Interpretation of recent Antarctic sea ice variability. Geophys Res Lett 31:L02205

Madec G (2008) NEMO ocean engine. Note du Pôle de Modélisation No. 27. Institut Pierre-Simon Laplace (IPSL), Paris

Masson S, Terray P, Madec G, Luo JJ, Yamagata T, Takahashi K (2012) Impact of intra-daily SST variability on ENSO characteristics in a coupled model. Clim Dyn 39: 681-707

Meehl GA (1991) A reexamination of the mechanism of the semiannual oscillation in the Southern Hemisphere. J Clim 4:911-926

Meehl GA, Hurrell JW, Van Loon H (1998) A modulation of the mechanism of the semiannual oscillation in the Southern Hemisphere. Tellus Ser A Dyn Meterol Oceanogr 50: 442-450

Mo KC, Paegle JN (2001) The Pacific-South American modes and their downstream effects. Int J Climatol 21:1211-1229

Mori M, Watanabe M, Shiogama H, Inoue J, Kimoto M (2014) Robust Arctic sea-ice influence on the frequent Eurasian cold winters in past decades. Nat Geosci 7:869-873

Morioka Y, Tozuka T, Yamagata T (2011) On the growth and decay of the subtropical dipole mode in the South Atlantic. J Clim 24:5538-5554

Morioka Y, Tozuka T, Masson S, Terray P, Luo JJ, Yamagata $\mathrm{T}$ (2012) Subtropical dipole modes simulated in a coupled general circulation model. J Clim 25:4029-4047

Morioka Y, Masson S, Terray P, Prodhomme C, Behera SK, Masumoto Y (2014) Role of tropical SST variability on the formation of subtropical dipoles. J Clim 27:4486-4507

Murphy EJ, Clarke A, Abram NJ, Turner J (2014) Variability of sea-ice in the northern Weddell Sea during the 20th century. J Geophys Res Oceans 119:4549-4572

Nakamura M (2012) Impacts of SST anomalies in the Agulhas Current system on the regional climate variability. J Clim 25:1213-1229

O'Kane TJ, Monselesan DP, Risbey JS (2017) A multiscale reexamination of the Pacific-South American pattern.

Editorial responsibility: Oliver Frauenfeld,

College Station, Texas, USA
Mon Weather Rev 145:379-402

Raphael MN (2003) Impact of observed sea-ice concentration on the Southern Hemisphere extratropical atmospheric circulation in summer. J Geophys Res 108:4687

* Reynolds RW, Rayner NA, Smith TM, Stokes DC, Wang W (2002) An improved in situ and satellite SST analysis for climate. J Clim 15:1609-1625

Roeckner E, Bäuml G, Bonaventura L, Brokopf R and others (2003) The atmospheric general circulation model ECHAM5. I. Model description. Rep 349. Max-PlanckInstitut für Meteorologie, Hamburg

Sen Gupta A, England MH (2006) Coupled ocean-atmosphere-ice response to variations in the Southern Annular Mode. J Clim 19:4457-4486

Takaya K, Nakamura H (1997) A formulation of a waveactivity flux for stationary Rossby waves on a zonally varying basic flow. Geophys Res Lett 24:2985-2988

* Takaya K, Nakamura H (2001) A formulation of a phaseindependent wave-activity flux for stationary and migratory quasigeostrophic eddies on a zonally varying basic flow. J Atmos Sci 58:608-627

Thompson DWJ, Wallace JM (2000) Annular modes in the extratropical circulation. I. Month-to-month variability. J Clim 13:1000-1016

UUdagawa Y, Tachibana Y, Yamazaki K (2009) Modulation in interannual sea ice patterns in the Southern Ocean in association with large-scale atmospheric mode shift. J Geophys Res 114:D21103

Valcke S, Caubel A, Vogelsang R, Declat D (2004) OASIS3 ocean atmosphere sea ice soil user's guide. Tech Rep TR/CMGC/04/68. CERFACS, Toulouse

*Venegas SA, Drinkwater MR (2001) Sea ice, atmosphere and upper ocean variability in the Weddell Sea, Antarctica. J Geophys Res 106:16747-16765

*Venegas SA, Mysak LA, Straub DN (1996) Evidence for interannual and interdecadal climate variability in the South Atlantic. Geophys Res Lett 23:2673-2676

*Venegas SA, Mysak LA, Straub DN (1997) Atmosphereocean coupled variability in the South Atlantic. J Clim 10:2904-2920

*Vigaud N, Richard Y, Rouault M, Fauchereau N (2009) Moisture transport between the South Atlantic Ocean and southern Africa: relationships with summer rainfall and associated dynamics. Clim Dyn 32:113-123

*Wall CJ, Kohyama T, Hartmann DL (2017) Low-cloud, boundary layer, and sea ice interactions over the Southern Ocean during winter. J Clim 30:4857-4871

Wilks DS (2016) 'The stippling shows statistically significant grid points': how research results are routinely overstated and overinterpreted, and what to do about it. Bull Am Meteorol Soc 97:2263-2273

\% Yuan X, Martinson DG (2000) Antarctic sea ice extent variability and its global connectivity. J Clim 13:1697-1717

Fuan X, Martinson DG (2001) The Antarctic dipole and its predictability. Geophys Res Lett 28:3609-3612

Y Yuan C, Tozuka T, Luo JJ, Yamagata T (2014) Predictability of the subtropical dipole modes in a coupled oceanatmosphere model. Clim Dyn 42:1291-1308

Zhang Z, Uotila P, Stössel A, Vihma T, Liu H, Zhong Y (2017) Seasonal southern hemisphere multi-variable reflection of the southern annular mode in atmosphere and ocean reanalyses. Clim Dyn (in press)

Submitted: June 2, 2017; Accepted: October 15, 2017 Proofs received from author(s): December 19, 2017 